Reading e-books on a near-to-eye display: Comparison between a small-sized multimedia display and a hard copy

\title{
Pölönen, Monika
}

2012-07-22

Pölönen , M , Järvenpää , T \& Häkkinen , J 2012 , ' Reading e-books on a near-to-eye display: Comparison between a small-sized multimedia display and a hard copy ' , Displays , vol. 33 , no. 3 , pp. 157-167 . https://doi.org/10.1016/j.displa.2012.06.002

http://hdl.handle.net/10138/35766

https://doi.org/10.1016/j.displa.2012.06.002

acceptedVersion

Downloaded from Helda, University of Helsinki institutional repository.

This is an electronic reprint of the original article.

This reprint may differ from the original in pagination and typographic detail.

Please cite the original version. 


\section{READING E-BOOKS ON A NEAR-TO-EYE DISPLAY: COMPARISON BETWEEN A SMALL-SIZED MULTIMEDIA DISPLAY AND A HARD COPY}

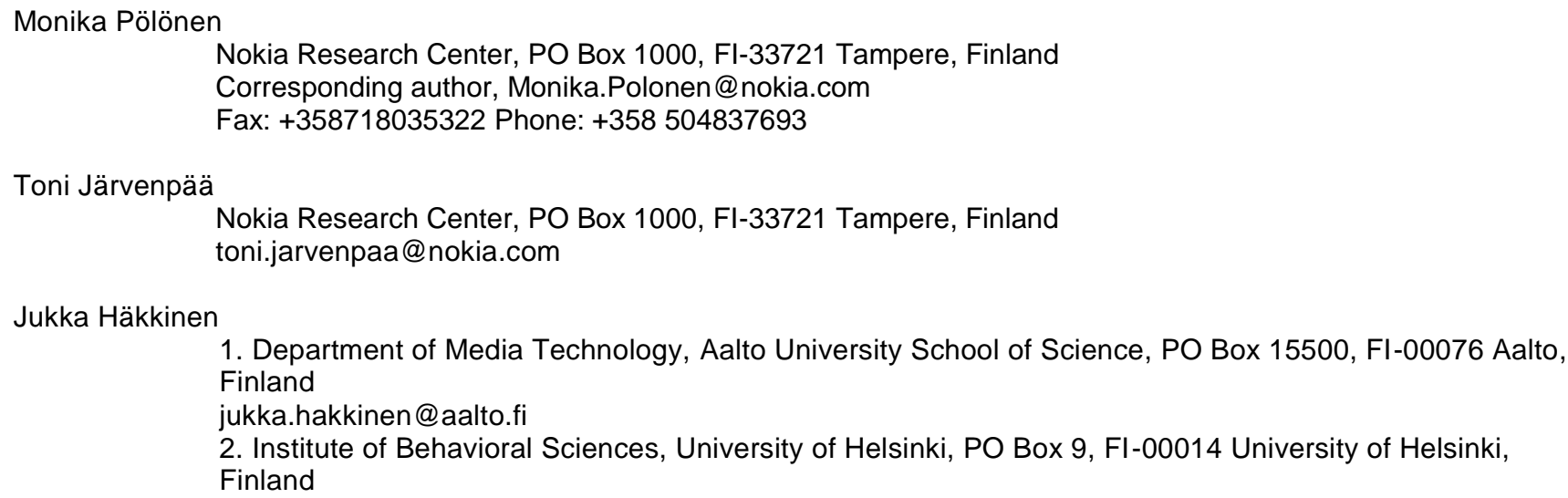

Displays 33(3) 157-167. (2012)

\section{Abstract}

Eighty-seven participants read an e-book either from a near-to-eye display, a small-size display or a hard copy. Eyestrain, visually induced motion sickness, changes in visual functioning, user experience, and the essential optical parameters of the reading equipment were evaluated. The results indicate that reading from a hard copy was the most comfortable experience. All near-to-eye displays induced eyestrain and sickness symptoms, but the magnitude of these symptoms varied according to the device. The adverse symptoms were related to problems with the display optics and design, text layout, headset fit, use context, and individual differences.

Keywords: near-to-eye display, small-sized display, eyestrain, discomfort, reading

Reading text is a complex and highly automated process during which readers extract visual information from the page and comprehend the text's meaning [1,2]. Depending on a reader's motivations, the text type, the media format, and the context, the process of reading varies between and within readers [3]. For example, reading a printed book may be an engrossing, effortless, and relaxing experience that lasts for hours, whereas reading the same text in electronic format may be a consciously demanding process because of poor text legibility and technology-related limitations $[3,4,5,2,74,75]$. As a result, the reader may experience frustration, fatigue, eyestrain or visual discomfort, which could affect reading-related practices $[6,7]$.

\subsection{The influence of text layout on reading}

During the past decades, several typographical factors have been shown to have an important role in text legibility (for a review, see [8,4,2]). According to Hill [2], designers of electronic books (e-books) should pay attention to the font typeface, font type size, inter-character and inter-word spacing, line length, full justification of lines, inter-line spacing, number of lines per page, page size and layout, as well as the internal navigation options. However, because reading on a screen is dependent on both the software and hardware characteristics, most of the published results related to reading experiences are dependent on the display characteristics, which are most often related to the display resolution and size.

Longer text lines on electronic screens are read faster, especially when the number of characters per line is increased [11,12,5]. Published results on typeface characteristics vary: Boyarski et al. [13] found no differences 
in text legibility between serif (Times and Georgia) and sans serif (Verdana) typefaces, whereas Bernard et al. [14] and Sheedy et al. [10] showed that sans serif typefaces were more legible on electronic screens than serif typefaces. In addition to typeface differences, pixel count, stroke width, and font smoothing have been shown to influence text legibility thresholds, and individual letters may be more important in the word identification process than word shapes [10]. Darroch et al. [15] found no reading performance or accuracy differences when font sizes from 6 to 16 were used on a small-size handheld display (HP iPAQ hx4700, resolution of 640x480 pixels). However, the participants preferred sizes from 8 to 12; the participants disliked smaller font sizes because of discomfort, whereas they claimed that a larger font size "[broke] up the flow of reading".

In summary, several typographical factors influence the reading performance, regardless of the media used. Advances in display technology, especially the increased resolution and development of device-related typographical features, have removed or reduced many text legibility problems. However, readers still seem to prefer to read printed documents, especially for in-depth reading (see also [16,17,2]). Working close to electronic displays has been shown to cause illness and eyestrain, which could be one important reason why subjects favor printed over electronic text $[6,7,19,18,20,21,22,23]$.

\subsubsection{Visual discomfort and near-to-eye displays}

As with other electronic displays, near-to-eye displays (NEDs) may induce eyestrain and viewing discomfort $[19,68,45]$. Because of unnatural viewing conditions, the use of NEDs can also lead to measurable physiological changes in visual functioning [38,37,39,20,22]. For instance, the goal of the vergence-accommodation interaction is to ensure that vision is both clear (the accommodation process) and single (the vergence process). Conflicting information in the cues presented on NED displays, especially in the binocular mode, for accommodation and vergence may change heterophoria values (e.g., [40,41]). Because several NED opticsrelated characteristics may affect visual functioning, different explanations for the same outcome have been offered. For example, Howarth [20] suggested that changes in heterophoria may be caused by the mismatch between the instrument's lenses (the inter-ocular distance) and the screens (the inter-screen distance), whereas Mon-Williams et al. [25] explained that changes in heterophoria values were caused by different vertical gaze angles (for an overview, see [41]).

In addition to eyestrain, the use of NEDs can induce sickness symptoms and discomfort [42,43,54,76,77]. For example, a long exposure duration [44,45,46,47,48], a large field-of-view [48,49,24], and task-related features such as visual simulation of motion $[50,51,52,36$,] may induce several sickness-related symptoms.

\subsection{Reading from small-sized displays and NEDs}

Although NEDs have been used as electronic vision enhancement displays for the visually impaired, the number of studies on the use of NEDs for reading tasks or as accessories for enhancement for small-sized displays is limited [62,63,55,36]. Sheedy and Bergstom [55] found a small increase in task performance speed when tasks were performed on near-eye displays compared to flat panel displays and hard copies. No changes in the visual acuity or heterophoria values occurred with any of the displays tested. These authors explained that the improved performance and comfort of NEDs were a result of the lack of movement in some tasks, partial immersion, better display resolution and concordance of the accommodative and vergence stimuli. Pölönen and 
Häkkinen [36] used an NED phone system with three typical multimedia tasks to study user experience and comfort. According to their results, using an NED as the viewing device for a mobile terminal could improve the viewing experience, increase the sense of presence and enable the performance of tasks that are otherwise not suited for such small devices. In addition, different tasks caused varying levels of eyestrain and sicknessrelated symptoms when the same NED phone system was used; game playing and film viewing were less demanding and induced fewer symptoms than text reading. However, the comparison of two situations, reading on a phone display (only pilot results) versus an NED, clearly brought out the advantages of the NED phone system.

\section{GOALS OF THE STUDY}

Because of the success of electronic media, people spend more time interacting with and viewing different media applications using various displays with different characteristics. However, it is important to recognize display-, content-, and context-related parameters that may impair task performance and decrease viewing comfort and to attempt to avoid or change them to ensure fun and comfortable experiences in the future. Thus, our main goals were to investigate the experiences of using a NED for a text reading task and to compare these experiences with those for small-sized displays and hard copies. In addition to general user experiences, we measured eyestrain, visually induced motion sickness, and changes in visual functioning after 20 and 40 min of reading.

Pölönen and Häkkinen 36 showed that a NED phone system could be used among other tasks for long-term reading, but, according to the authors, a reading session duration of 40 min might be too long, making a shorter duration more suitable when tasks comparable to reading are performed. Our main goal in experiment 1 was to investigate the meaning of the duration of immersion during the reading tasks when a NED phone system was used, whereas in experiment 2 , the goal was to compare the reading experiences for different media formats for e-book reading.

\section{EXPERIMENT 1}

\subsection{Method}

Because one of the goals was to compare results from experiments 1 and 2, most of the Tables and Figures include the information/results from both experiments; the iTheater NED setup from Experiment 1 and other devices from Experiment 2. Moreover, a comparison of subjective experiences and opinions will be mostly presented in section 4.2.

\subsubsection{Procedure}

Each test session began with a visual screening (visual acuity, interpupillary distance (IPD), stereo acuity, color vision, near horizontal phoria, and the near point of accommodation). Participants then completed a questionnaire containing background questions (name, gender, age, NED experience, computer usage, and vulnerability to motion sickness/headache) and questions related to eyestrain [7,64] and visually induced motion sickness [42]. The eyestrain questionnaire (VSQ) measures the severity of eyestrain-related symptoms (tired eyes, sore or aching eyes, irritated eyes, watering or runny eyes, dry eyes, hot or burning eyes, blurred vision, 
double vision, general visual discomfort) that are often connected to the computer vision syndrome [76]. The simulator sickness questionnaire (SSQ) measures symptoms of motion sickness related to specific use environments $[19,48,67]$. The subscales, i.e., the oculomotor symptoms (O: general discomfort, fatigue, headache, eyestrain, difficulty focusing, difficulty concentrating, and blurred vision, weight 7.58), disorientation (D: difficulty focusing, nausea, fullness of head, blurred vision, dizzy with eyes open and closed, vertigo; weight 13.92), and nausea ( $\mathrm{N}$ : general discomfort, increased salivation, sweating, nausea, difficulty concentrating, stomach awareness and burping; weight 9.54) provide more specific information about the nature of the sickness, whereas the total sickness score reflects the overall discomfort level (T: weight 3.74). In both questionnaires, each symptom was rated by the individual as either "none," "slight," "moderate,"or "severe."

In the next step, participants were introduced to the task, and they were asked to read a Finnish translation of an e-book Uncle Bernac (from the Project Gutenberg free online catalog) for 40 minutes. The text, black letters on a white background, was presented in landscape format; approximately 700 characters were simultaneously visible (Fig. 1, iTheater NED). The subjects used page-by-page vertical scrolling to proceed. Although several symbol- and text layout-related parameters have been shown to affect legibility (e.g., $[2,4,5,65,66])$, we did not edit these parameters because one of our goals was to maintain the settings that were similar to those typically used. After $20 \mathrm{~min}$, the reading was interrupted, and participants completed the VSQ and SSQ questionnaires. After $40 \mathrm{~min}$, participants once again answered several experience-, task-, and equipment-related questions (e.g., task interest and pleasantness, physical ergonomics, opinion change, image quality, SSQ, and VSQ). To guarantee fluent reading, the leader of the experiment asked the questions and marked the answers on the answer sheet. The laboratory was dimmed during the tests (10 lux). In total, one testing session lasted one hour.

\subsubsection{Equipment}

We used an EMG iTheater BP4L commercial NED as the viewing device. This model was chosen because it represented a typical NED in the consumer market during the time of the tests. The text was presented from an N95 8 GB phone via a composite video signal. Both the phone display and the NED had a Quarter Video Graphics Array (QVGA) resolution of 320 x 240 pixels. However, the video signal had a different, higher resolution, and the image was scaled and shown in the NED with black borders. Thus, the observable resolution was slightly degraded compared to the original QVGA. We measured the main optical parameters with an optimized characterization system for NEDs [54]. The field-of-view (FOV) of the image was approximately 23 and 17 degrees in the horizontal and vertical directions, respectively (Table 1, iTheater NED). The focal and convergence distances of the images were approximately $2 \mathrm{~m}$ for subjects with an average interpupillary distance. The contrast ratio was 62:1, on average. A 10-point sans serif font was used without antialiasing, whereas the font stroke width (one pixel) in the NED was approximately 4 minutes of arc. The minimum character height was 31 minutes of arc. 
Experiment 2: Paper page 1

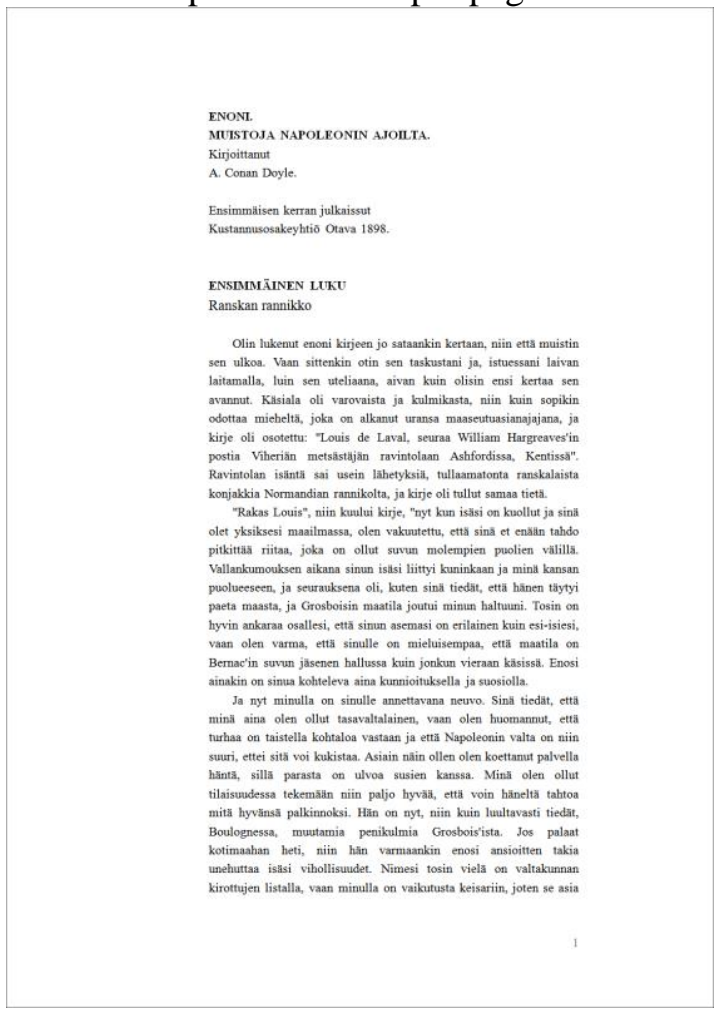

Experiment 2: N900 page 3

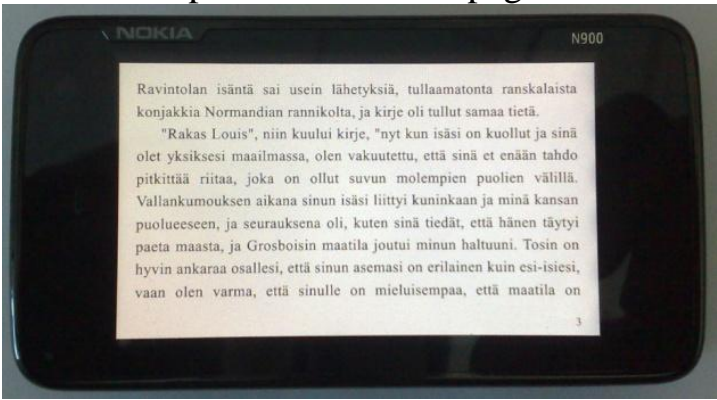

Experiment 1: iTheater NED page 6

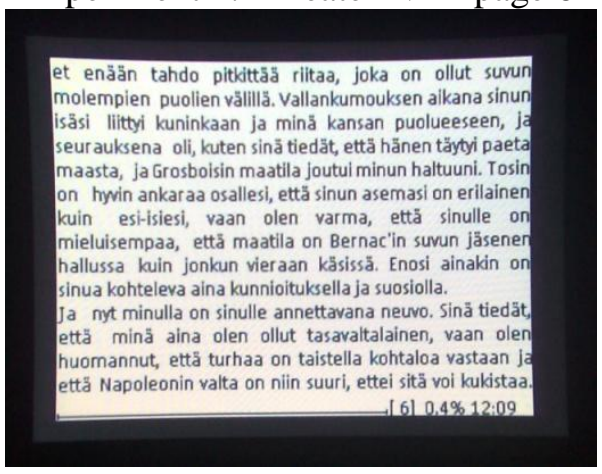

Experiment 2: Zeiss NED page 3

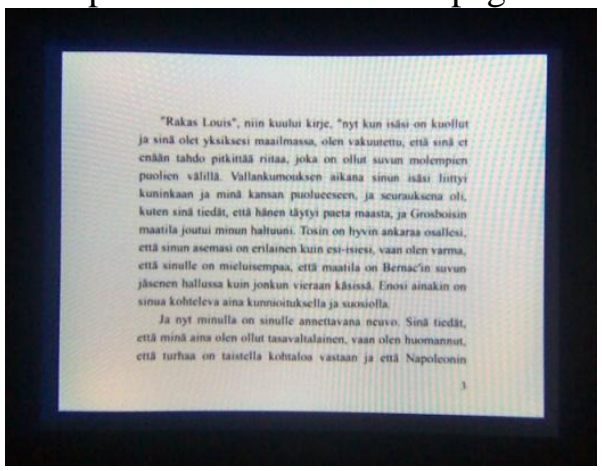

Experiment 2: Vuzix NED page 3

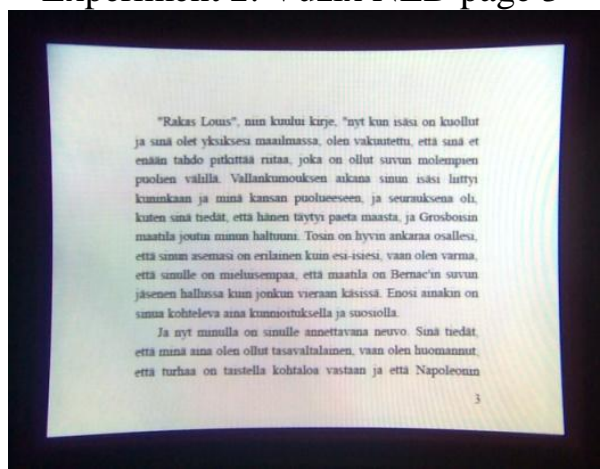

Fig.1. The text layouts in the different media for experiments 1 and 2. The NED screenshots have the same relative size. 
Table 1. The characteristics of the reading equipment for experiments 1 and 2 .

\begin{tabular}{|c|c|c|c|c|c|c|c|c|}
\hline \multirow[b]{2}{*}{ Characteristic } & \multicolumn{2}{|c|}{ iTheater BP4L } & \multicolumn{2}{|c|}{ Zeiss Cinemizer Plus } & \multicolumn{2}{|c|}{ Vuzix Wrap 920} & \multirow{2}{*}{ Nokia N900 } & \multirow{2}{*}{ Paper } \\
\hline & left & right & left & right & left & right & & \\
\hline Resolution & \multicolumn{2}{|c|}{$320 \times 240$} & \multicolumn{2}{|c|}{$640 \times 480$} & \multicolumn{2}{|c|}{$640 \times 480$} & $3.5 " 800 \times 480$ & A4 600 dpi \\
\hline Pixel size & \multicolumn{2}{|c|}{$4,4^{\prime}$ of arc } & \multicolumn{2}{|c|}{$2.4^{\prime}$ of arc } & \multicolumn{2}{|c|}{$2,3^{\prime}$ of arc } & $0.8^{\prime}$ of $\operatorname{arc}(267 \mathrm{ppi})$ & $0.4^{\prime}$ of $\operatorname{arc}(600 \mathrm{dpi})$ \\
\hline Image source & \multicolumn{2}{|c|}{ Nokia N95 8GB } & \multicolumn{2}{|c|}{ Apple iPod 30GB } & \multicolumn{2}{|c|}{ HP laptop } & Adobe PDF reader & Xerox laser printer \\
\hline Connection type & \multicolumn{2}{|c|}{ Composite video } & \multicolumn{2}{|c|}{ Composite video } & \multicolumn{2}{|c|}{ VGA video } & NA & NA \\
\hline Contrast ratio & $66: 1$ & $58: 1$ & $36: 1$ & $52: 1$ & $49: 1$ & $69: 1$ & $150: 1$ & $20: 1$ \\
\hline Focal distance & $2.2 \mathrm{~m}$ & $2.0 \mathrm{~m}$ & $1.1 \mathrm{~m} *)$ & $1.2 \mathrm{~m} *)$ & $0.5 \mathrm{~m} *)$ & $0.5 \mathrm{~m} *)$ & $\sim 0.4 \mathrm{~m}$ & $\sim 0.4 \mathrm{~m}$ \\
\hline Convergence dist. & \multicolumn{2}{|c|}{$1.7 \mathrm{~m}$} & \multicolumn{2}{|c|}{$1.4 \mathrm{~m}$} & \multicolumn{2}{|c|}{$3.0 \mathrm{~m}$} & $\sim 0.4 \mathrm{~m}$ & $\sim 0.4 \mathrm{~m}$ \\
\hline Hor. FOV display & \multicolumn{2}{|c|}{$23.2^{\circ}$} & \multicolumn{2}{|c|}{$25.2^{\circ}$} & \multicolumn{2}{|c|}{$24.0^{\circ}$} & $76 \mathrm{~mm} / \sim 10.9^{\circ}$ & $210 \mathrm{~mm} / \sim 29.4^{\circ}$ \\
\hline Hor. FOV text & \multicolumn{2}{|c|}{$23.0^{\circ}$} & \multicolumn{2}{|c|}{$16.6^{\circ}$} & \multicolumn{2}{|c|}{$16.6^{\circ}$} & $70 \mathrm{~mm} / \sim 10.0^{\circ}$ & $110 \mathrm{~mm} / \sim 15.7^{\circ}$ \\
\hline Ver. FOV text & \multicolumn{2}{|c|}{$16.5^{\circ}$} & \multicolumn{2}{|c|}{$12.6^{\circ}$} & \multicolumn{2}{|c|}{$12.6^{\circ}$} & $34 \mathrm{~mm} / \sim 4.9^{\circ}$ & $232 \mathrm{~mm} / \sim 32.3^{\circ}$ \\
\hline Min. character height & \multicolumn{2}{|c|}{$31^{\prime}$ of arc } & \multicolumn{2}{|c|}{$17^{\prime}$ of arc } & \multicolumn{2}{|c|}{$17^{\prime}$ of arc } & $1.1 \mathrm{~mm} / \sim 9.5^{\prime}$ of arc & $1.8 \mathrm{~mm} / \sim 15^{\prime}$ of arc \\
\hline Page: lines/characters & \multicolumn{2}{|c|}{$14 / 50$} & \multicolumn{2}{|c|}{$14 / 55$} & \multicolumn{2}{|c|}{$14 / 55$} & $10 / 60$ & $42 / 60$ \\
\hline Font typeface & \multicolumn{2}{|c|}{ Sans serif } & & rif & & rif & Serif & Serif \\
\hline Ambient illumination & & & 250 & lux & 250 & $\operatorname{lux}$ & $250 \operatorname{lux}$ & $1000 \operatorname{lux}$ \\
\hline
\end{tabular}

\subsubsection{Participants}

Twenty participants, 10 males and 10 females between 23 and 53 years of age (mean 34.9 years), participated in the test. Six participants had previous experience with NEDs, but only four of the participants were familiar with virtual reality systems (e.g., CAVE). Thirteen participants used eyeglasses daily, and the average user IPD was $63.65 \mathrm{~mm}$. All the participants were experienced computers users, and the mean usage for a typical week was 38.5 hours. Three participants reported high susceptibility to motion sickness by selecting the option "Often" in response to a questionnaire item related to the frequency of motion sickness. All the participants felt normal before the test; they did not report feeling tired, ill, exhausted, stressed or otherwise incapable of participating.

\subsection{Results and discussion}

Non-parametric test procedures (Mann-Whitney U, Kruskal-Wallis H, Friedman, Kendall's W, and Wilcoxon) were used for the statistical analysis because the data were not normally distributed and some dependent variables were measured on ordinal scales.

\subsubsection{Visually induced motion sickness and eyestrain}

A comparison of symptom levels before and after the experiments, based on Friedman and Kendall's tests, clearly revealed that all sickness subscales (oculomotor symptoms, nausea, disorientation), as well as the SSQ total score and eyestrain (VSQ) scores, were significantly different for different measurement times (Table 2, iTheater).

A more detailed pair comparison within symptom subgroups showed that the nausea scores were significantly higher $40 \mathrm{~min}$ after immersion than they were before the test, and the increase in the nausea scores was statistically significant in the second half of the experiment (for statistics, see Table 3 and Fig. 2, iTheater). 
Both eyestrain scores and oculomotor symptom levels were significantly higher after 40 min compared to symptom levels before the test. Additionally, the increases in the ocular symptom levels were significant in both the first and second halves of the experiment. The disorientation levels increased significantly during the second half of the experiment. Because several significant changes in the sickness subscale scores were observed, especially in the second half of the experiment, the total symptom severity scores (i.e., the sum of the nausea, disorientation and oculomotor symptoms) were significantly different for changes before and after the test and after $20 \mathrm{~min}$.

Reading and working close to electronic screens has been shown to cause eyestrain and viewing discomfort, and thus, some increase in symptom levels was expected [34,7,36,39,26,22,6,68]. However, because we maintained settings that were similar to those typically used, there are many possible reasons for the increased symptom levels. Eyestrain could have been increased by the low screen resolution of the NED [6,7] (Table 1, iTheater), the unusual viewing angle (a portion of the image was above the line of sight) (Fig. 1, iTheater) [7,6,29,27,32,31], and the long line lengths in both the vertical and horizontal directions $[6,7,18,20]$. The increases in dizziness in the second half of the test could be explained by a non-optimized text layout (no margins and large type size), mild optical distortions, and headset movement relative to the head [5, 15].

Nausea symptoms have been previously associated with sensory conflicts, which usually occur when a person is watching a moving scene, but they may also occur under static stimuli viewing conditions $[23,21,36,33,45,50]$. Thus, increases in the nausea scores in our tests with static stimuli could have been a result of the interactions of several parameters: reading duration (40 $\mathrm{min}$ ), mild optical screen distortion (flickering and pincushion distortion), text layout (e.g., no margins and type size), the movement of the headset relative to the head during the task, and dark laboratory illumination (e.g., [21,4,39,7,27,26,45,67]).

Thus, the increased symptom scores, particularly in the second half of the reading session, were likely a result of interactions among the following factors: the nature of the task, optical characteristics and distortion of the display, headset fit, use context, and duration of the reading session [4,7,10,21,22,25,30,32,41,44,45,48,54]. The results support earlier findings that associated several causal factors with simulator sickness, but not all factors are necessary for the occurrence of symptoms (cf., $[48,21]$ ). Because only one NED model was tested, these results cannot be generalized to other NEDs; however, it seems that using a NED phone system with a text layout similar to the tested one is a relatively comfortable experience during the first 20 minutes. After 20 min, reading from a NED may induce unwanted symptoms, thus making the reading experience less comfortable. To better gauge the user experience for e-books read from NEDs, the same setup, with some improvements, was used to study two other NEDs, and the results were compared with the results for reading from a hard copy and a small-size display. 
Table 2. The overall comparison of symptom levels using Kendall's W and Friedman test procedures for several related samples $(\mathrm{N}=$ nausea, $\mathrm{O}=$ oculomotor symptoms, $\mathrm{D}=$ disorientation, $\mathrm{T}=$ total symptom severity and VSQ=eyestrain). Only significant differences for each display/subscale are presented.

\begin{tabular}{|c|c|c|c|c|c|c|}
\hline Display & Test statistics & $\mathrm{N}$ & $\mathrm{O}$ & $\mathrm{D}$ & $\mathrm{T}$ & $\mathrm{V}$ SQ \\
\hline iTheater & $\mathrm{N}$ & 20 & 20 & 20 & 20 & 20 \\
& Kendall's W & 0.305 & 0.379 & 0.152 & 0.407 & 0.244 \\
& Chi-Square & 12.182 & 15.176 & 6.063 & 16.291 & 9.759 \\
& $\mathrm{df}$ & 2 & 2 & 2 & 2 & 2 \\
& Asymp. Sig. & 0.002 & 0.001 & 0.048 & 0.000 & 0.008 \\
\hline Vuzix & $\mathrm{N}$ & & 20 & 20 & 20 & 20 \\
& Kendall's W & & 0.475 & 0.222 & 0.459 & 0.530 \\
& Chi-Square & & 18.984 & 8.897 & 18.375 & 21.194 \\
& $\mathrm{df}$ & & 2 & 2 & 2 & 2 \\
& Asymp. Sig. & & 0.000 & 0.012 & 0.000 & 0.000 \\
\hline Zeiss & $\mathrm{N}$ & & 21 & 21 & 21 & 21 \\
& Kendall's W & & 0.368 & 0.200 & 0.368 & 0.438 \\
& Chi-Square & & 15.474 & 8.400 & 15.474 & 18.392 \\
& $\mathrm{df}$ & & 2 & 2 & 2 & 2 \\
& Asymp. Sig. & & 0.000 & 0.015 & 0.000 & 0.000 \\
\hline Phone & $\mathrm{N}$ & & 13 & & 13 & 13 \\
& Kendall's W & & 0.334 & & 0.393 & 0.751 \\
& Chi-Square & & 8.696 & & 10.231 & 19.538 \\
& $\mathrm{df}$ & & 2 & & 2 & 2 \\
& Asymp. Sig. & & 0.013 & & 0.006 & 0.000 \\
\hline \multirow{5}{*}{ Hard copy } & $\mathrm{N}$ & & & & & 13 \\
& Kendall's W & & & & & 0.435 \\
& Chi-Square & & & & & 11.313 \\
& Asymp. Sig. & & & & & 2 \\
& & & & & & 0.003 \\
\hline
\end{tabular}

Table 3. A pairwise comparison of symptom levels after different reading durations using a Wilcoxon's signed ranked test for repeated measurements. A Holm-Bonferroni correction was used to control for occurrence of false positive p-values. (1$2=0-20 \mathrm{~min}, 2-3=20-40 \mathrm{~min}, 1-3=0-40 \mathrm{~min})$. $(\mathrm{N}=$ nausea, $\mathrm{O}=$ oculomotor symptoms, $\mathrm{D}=$ disorientation, $\mathrm{T}=$ total symptom severity and VSQ=eyestrain). Only significant differences are presented.

\begin{tabular}{|c|c|c|c|}
\hline Display & Pair & $Z$ value & $\begin{array}{c}\text { Asymp. Sig. (2- } \\
\text { tailed) }\end{array}$ \\
\hline iTheater & $\mathrm{N} 2-3$ & $-2,588$ & 0,03 \\
\hline \multirow[t]{8}{*}{$\mathrm{N}=20$} & N1-3 & $-2,539$ & 0,022 \\
\hline & $01-3$ & $-2,911$ & 0,012 \\
\hline & $\mathrm{O} 2-3$ & $-2,831$ & 0,01 \\
\hline & $\mathrm{O} 1-2$ & $-2,031$ & 0,042 \\
\hline & D2-3 & $-2,428$ & 0,045 \\
\hline & $\mathrm{T} 2-3$ & $-3,215$ & 0,003 \\
\hline & $\mathrm{T} 1-3$ & $-2,821$ & 0,01 \\
\hline & VSQ1-3 & $-2,835$ & 0,015 \\
\hline Vuzix & $01-3$ & $-3,454$ & 0,003 \\
\hline \multirow[t]{9}{*}{$\mathrm{N}=20$} & O1-2 & $-2,839$ & 0,01 \\
\hline & $\mathrm{O} 2-3$ & $-3,454$ & 0,017 \\
\hline & D1-3 & $-2,456$ & 0,042 \\
\hline & D1-2 & $-2,251$ & 0,048 \\
\hline & $\mathrm{T} 1-3$ & $-3,354$ & 0,003 \\
\hline & $\mathrm{T} 1-2$ & $-2,807$ & 0,01 \\
\hline & VSQ1-3 & $-3,48$ & 0,003 \\
\hline & VSQ1-2 & $-3,106$ & 0,004 \\
\hline & VSQ2-3 & $-2,654$ & 0,008 \\
\hline Zeiss & $01-2$ & $-3,082$ & 0,006 \\
\hline \multirow[t]{6}{*}{$\mathrm{N}=21$} & $01-3$ & $-3,082$ & 0,004 \\
\hline & $\mathrm{T} 1-2$ & $-3,114$ & 0,006 \\
\hline & $\mathrm{T} 1-3$ & $-3,096$ & 0,004 \\
\hline & VSQ1-3 & $-3,184$ & 0,003 \\
\hline & VSQ1-2 & $-2,952$ & 0,009 \\
\hline & VSQ2-3 & $-2,49$ & 0,013 \\
\hline Phone & VSQ1-3 & $-2,966$ & 0,009 \\
\hline \multirow[t]{2}{*}{$\mathrm{N}=13$} & VSQ2-3 & $-2,751$ & 0,012 \\
\hline & VSQ1-2 & $-2,64$ & 0,008 \\
\hline $\begin{array}{c}\text { Hard copy } \\
\mathrm{N}=13\end{array}$ & VSQ1-3 & $-2,484$ & 0,039 \\
\hline
\end{tabular}



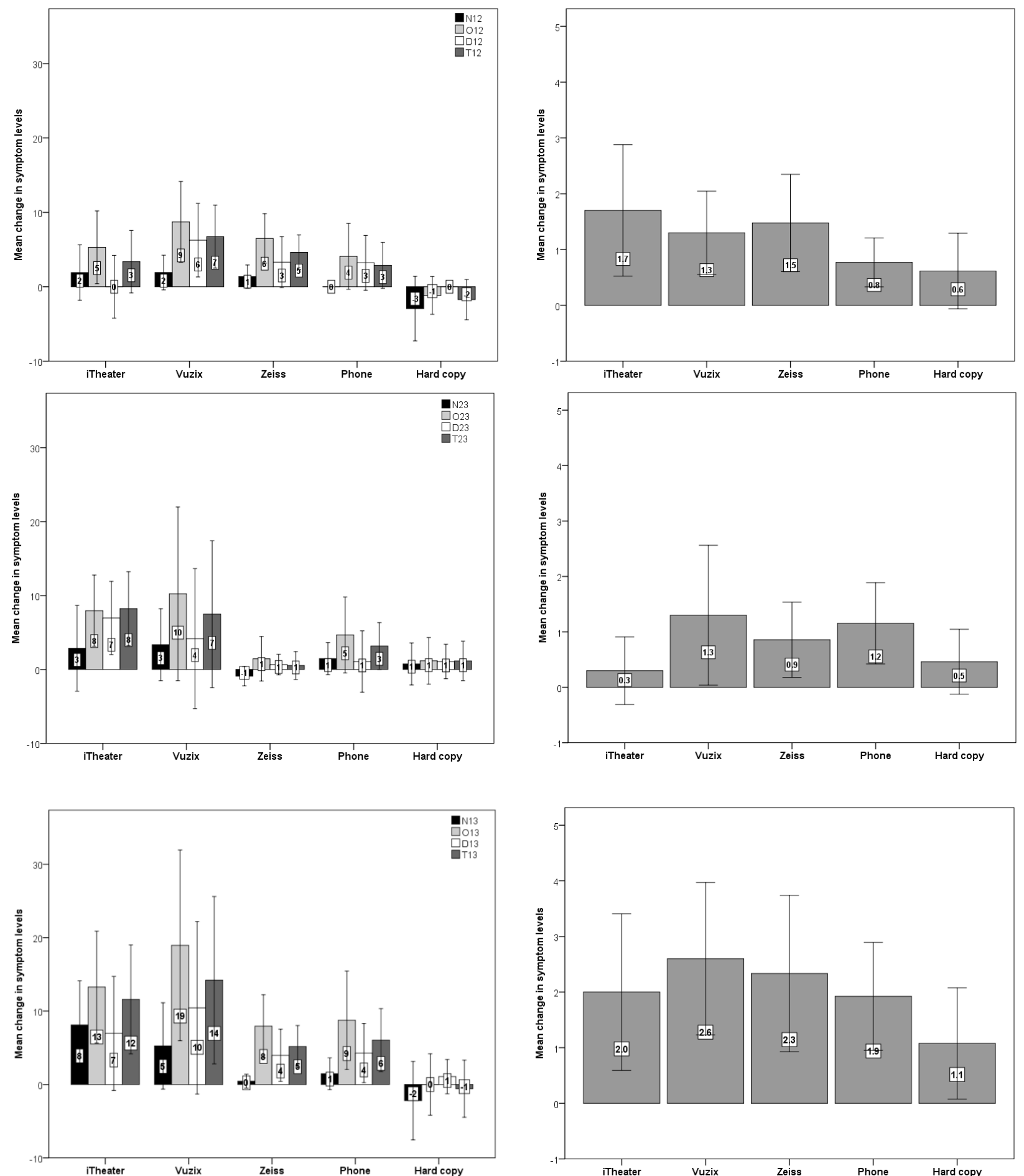

Fig. 2. The mean changes in symptom levels $(\mathrm{SSQ}=$ left and eyestrain $=$ right $)$. For eyestrain, an increase of 1 point means one new symptom or a mild increase in symptom severity. For SSQ, $\mathrm{N}=$ nausea, and the symptom weight was 9.54 ; $\mathrm{O}=$ oculomotor symptoms, and the weight was 7.58; $\mathrm{D}=$ disorientation, and the weight was $13.92 ; \mathrm{T}=$ total symptom severity, and the weight was 3.74 . Top row, 12 = 0-20 min; middle row, $23=20-40 \mathrm{~min}$; bottom row, $13=0-40 \mathrm{~min}$. Vertical lines represent standard errors. Numbers in the columns are mean symptom scores for specific devices. Negative values refer to a decrease in symptom levels; a 0 means no change; and a positive value indicates an increase in symptom levels. 


\section{EXPERIMENT 2}

\subsection{Method}

\subsubsection{Procedure}

Similar to Experiment 1, each test session began with a short introduction to the experiment followed by a visual screening (visual acuity near and far, IPD, stereo acuity, color vision, heterophoria, near point of accommodation (AC)). After the introduction, participants completed the SSQ 42 and VSQ [64] and answered some experience- and background-related questions. Participants were then asked to read an e-book for 40 minutes (section 3.1.1). The text characteristics and layouts for each medium (font typefaces, font type sizes, line lengths, fully justified lines, interline spacing, number of lines per page and page size) were optimized [2] (Table 1). As in experiment 1, page-by-page scrolling, black letters on a white background, and landscape format on electronic screens were utilized (Fig. 1). In contrast to experiment 1, experiment 2 used different laboratory illumination conditions: the brightness was high enough to enable reading from paper (1000 lux) and low enough to reduce glare and unwanted reflections on NEDs (250 lux). The viewing angle and viewing distance were controlled by a chin rest when a paper and phone setups were used (Fig. 3).

After 20 min, the reading was interrupted, and the AC, heterophoria, and near visual acuity were measured. Participants were asked to answer the sickness- and eyestrain-related questionnaires again and then continued reading for another 20 minutes. Immediately after the tasks, the AC, heterophoria, and near visual acuity were re-measured, and the SSQ and VSQ questionnaires were completed the third time. Additionally, participants evaluated the display quality, NED-related experiences, and content of the text by answering several oral and/or written questions.

\subsubsection{Equipment}

We chose two widely available NED devices: the Zeiss Cinemizer Plus and the Vuzix Wrap 920. The companies that manufacture these devices have reasonably long histories in the NED business and seem to continuously launch new NED devices. The results were compared to those from reading a hard copy (A4 paper with printed text) and a small-sized display (Nokia N900 mobile computer). The reading setups for these different media are shown in Fig. 3. A viewing distance of $0.4 \mathrm{~m}$ was used for the hard copy and phone setups. As optical design and eye separation distance affect the actual viewing distance with NEDs, the viewing distance cannot be stated ambiguously. Instead, we measured the virtual image focal distances in the optical axes of the left and right eye optical setups, as well as the convergence distance. These distances are listed in Table 1. Unlike for the direct-view reading devices (paper and N900), head movements with immersive NEDs do not affect the visual field: eye movements alone are used to scan text in both the vertical and horizontal directions. Different page scrolling techniques could have reduced the required eye movements, but such methods were not used (e.g., due to motion blurring). 


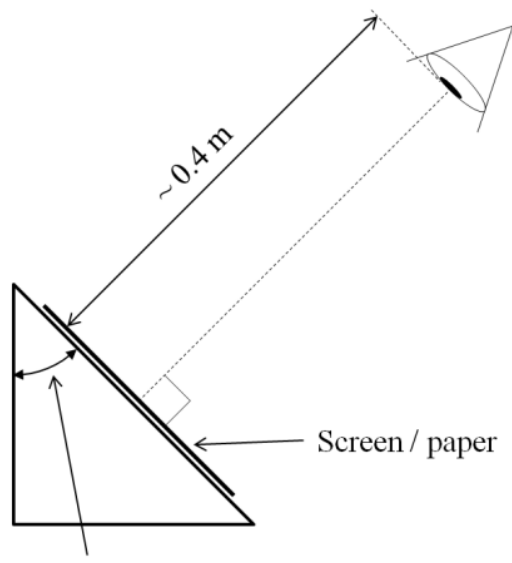

Tilt angle $45^{\circ}$

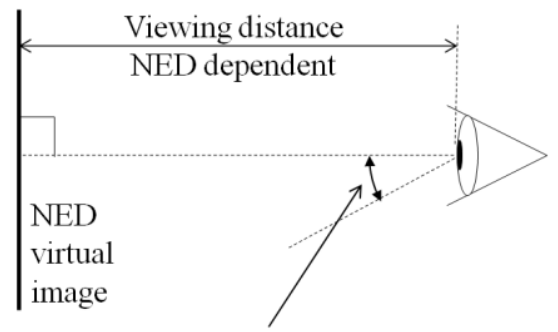

Tilt angle $\sim 0^{\circ}$ by design

Fig. 3. The N900 screen and paper were set at a $45^{\circ}$ angle at a viewing distance of approximately $0.4 \mathrm{~m}$. With NEDs, the virtual image is located close to the line of sight, but the actual tilt angle changes with the head movements. The viewing distance cannot be explicitly stated for NEDs due to a mismatch in the accommodation and vergence.

Both NEDs were similar according to the published specifications. Compared to the iTheater NED from experiment 1 , the most noticeable difference was the display panel resolution: $640 \mathrm{x} 480$ as opposed to $320 \mathrm{x}$ 240. However, the panel size is only one of the factors that affects the resolution; optical design and the connection type also affect image quality. Image sharpness was not measured optically. During both the optical measurements and the expert evaluations, the image sharpness on the Zeiss NED was lower than that of the Vuzix NED. Even though the panel resolution was the same for these NEDs, the video interface was different in the experiment. The Vuzix NED was connected to a laptop via a Video Graphics Array (VGA) video connection, whereas the Zeiss NED used a composite video connection with lower-resolution data throughput. Due to a flicker for high contrast areas in the composite video, filtering (smoothing) was used to soften the text outlines, which were softer than those of the Vuzix NED. With the composite video connection, the native display resolution cannot be used, and imperfect pixel interpolation further degrades the image quality.

In addition to attempting to optimize the text characteristics for each reading device, we attempted to match the viewing layouts and field-of-views of the text columns for fair comparison, when possible. The text on paper and the NED screens had horizontal FOVs of approximately $16^{\circ}$, whereas the N900 had a much lower FOV $\left(\sim 10^{\circ}\right)$ and a smaller margin due to the smaller screen size. The small difference in the display FOV of the NEDs was accounted for by adding black borders to the images for the Cinemizer. The character size was set to 15 min of arc (minimum lower case character height) on the paper. This size was too small (text blurred) for the NEDs, and therefore, the font size was enlarged slightly to $17^{\prime}$ of arc. With the N900, the character height was optimized to approximately 10 ' of arc. Trying to match the viewing parameters between different reading setups clearly resulted in a compromise. For example, the pixel resolution of printed paper exceeded that of the human visual system [78,79]. However, the pixel size in the NEDs was approximately 2-3 minutes of arc. The observed resolution was even worse due to the optical aberrations of the display and was far from matching the visual system.

Similar to experiment 1 , we measured the optical characteristics of these devices. Table 1 summarizes the display- and text-related characteristics of experiments 1 and 2. 


\subsubsection{Participants}

A total of 67 subjects, 34 males and 33 females from 29 to 50 years of age (mean 38.7 years), participated in four different experimental setups and read an e-book from a hard copy $(\mathrm{N}=13)$, a mobile device $(\mathrm{N}=13)$, a Zeiss NED ( $\mathrm{N}=21$, average user IPD was $61.8 \mathrm{~mm})$ or a Vuzix NED $(\mathrm{N}=20$, average user IPD was $60 \mathrm{~mm})$. All participants had normal or corrected to normal vision, no deficiencies in red/green color vision, and stereo vision acuity of less than or equal to 30 seconds of arc. As in experiment 1, all participants were experienced computer users, and the mean usage time for a typical week was 39 hours. Forty-six participants had previous experience with NEDs, but only twenty participants were familiar with virtual reality systems (e.g., CAVE). Thirty-three participants used eyeglasses daily (52\% of participants in the Zeiss setup and $45 \%$ in the Vuzix setup) and also during the tests. All participants felt normal before the test.

\subsection{Results and discussion}

Non-parametric tests, including the Mann-Whitney U, Kruskal-Wallis H, Friedman, Kendall's W, Wilcoxon, and Kendall's correlation tests, were used for the statistical analyses. In addition we compared the results from experiment 2 to the results from experiment 1.

\subsubsection{Visually induced motion sickness and eyestrain}

Similar to the results of experiment 1, both NEDs induced eyestrain, disorientation, and oculomotor symptoms (Table 2 and 3 and Fig. 2). However, no changes in nausea scores were observed. Fig. 2 shows that there were no clear trends in symptom changes during the 40-min reading session; use of the Vuzix NED caused relatively similar changes in eyestrain and visually induced motion sickness levels in the first and second halves of the experiment; use of the Zeiss NED induced more symptoms in the first half than in the second and use of the iTheater NED caused less eyestrain and more visually induced motion sickness symptoms in the second half than the first.

Both control setups, a mobile device and a hard copy, induced some increase in eyestrain but did not significantly change the disorientation or nausea values (Table 2, 3 and Fig. 3). According to the readers' oral comments and the eyestrain scores, reading from the small display of the mobile device was clearly more demanding in the second half of the experiment $[36,6,7,45,44,46,47]$. At the end of the test session, six readers mentioned that the characters could have been bigger, especially in the second half of the experiment, but no subject wanted to reduce the total number of characters visible at one time. The only negative feature of the hard copy was related to the text layout: two participants stated that the pages contained too many lines.

Comparing the symptom levels among the NEDs, a small-size display, and a hard copy revealed significant differences among the media formats in oculomotor symptom levels after reading for $20 \mathrm{~min}\left(\chi^{2}=10.53, \mathrm{df}=2\right.$, $\mathrm{p}=0.005)$ and $40 \mathrm{~min}\left(\chi^{2}=10.67, \mathrm{df}=2, \mathrm{p}=0.005\right)$ and in the total symptom severity levels after $20 \mathrm{~min}\left(\chi^{2}=9.87\right.$, $\mathrm{df}=2, \mathrm{p}=0.007)$ and $40 \mathrm{~min}\left(\chi^{2}=10.04, \mathrm{df}=2, \mathrm{p}=0.007\right)$. The post-hoc test (Mann-Whitney $\mathrm{U}$, Table 4) showed that the use of NEDs induced significantly more oculomotor and nausea symptoms and higher total symptom severity scores compared to the use of a hard copy.

Thus, our findings support earlier conclusions about the dependence of symptom patterns associated with the use of NEDs on specific devices or systems (see Howarth (1997) in [68]). Moreover, changes in the different 
symptom levels could not be explained with a single explanatory variable, although some factors could have had a stronger effect than others (cf., [21,48,43]). For example, we can assume that significant differences in the Vuzix NED's focal and convergence distances (see Table 1) caused some changes in the disorientation and eyestrain levels, but, according to the subjective comments, headset movement relative to the head and an unnatural viewing angle also affected the symptom levels [7,40,41,54]. Because other NEDs also induced symptoms of disorientation compared with other media formats, it seems that tasks demanding long-term concentration on small details similar to reading may make the user more sensitive to headset movements relative to the head and text. Thus, reading an e-book from a NED display demands a good headset fit, but the viewing comfort may also depend on the visibility of the surrounding context, which, in turn, may set some demands on the display size.

As expected, reading an e-book from a hard copy was the most comfortable experience. Reading from a small size display was also a relatively comfortable experience, in particular during the first $20 \mathrm{~min}$. However, in spite of the limitations in the characters' sizes, after $40 \mathrm{~min}$, the overall symptom levels remained lower than with some of the NEDs. Thus, high resolution and a lack of visible distortions in the text improve reading experiences, but bigger display sizes are preferred for long-term reading.

Table 4. Significant changes in symptom subgroups when pairs of media formats were compared $(\mathrm{N}=$ nausea, $\mathrm{O}=$ oculomotor symptoms, $\mathrm{T}=$ total symptom severity, $12=0-20 \mathrm{~min}, 23=20-40 \mathrm{~min}$, and $13=0-40 \mathrm{~min}$ ).

\begin{tabular}{|l|l|r|r|r|r|}
\hline & & \multicolumn{1}{c|}{$\mathrm{O} 12$} & \multicolumn{1}{c|}{$\mathrm{T} 12$} & \multicolumn{1}{c|}{$\mathrm{O} 13$} & \multicolumn{1}{c|}{$\mathrm{T} 13$} \\
\hline \multirow{2}{*}{ NED - Hard copy } & Mann-Whitney U & 188,500 & 191,500 & 175,000 & 181,500 \\
& Wilcoxon W & 279,500 & 282,500 & 266,000 & 272,500 \\
& Z & $-3,100$ & $-3,036$ & $-3,232$ & $-3,111$ \\
& Asymp. Sig. (2-tailed) &, 002 &, 002 &, 001 &, 002 \\
\hline
\end{tabular}

\subsubsection{Changes in visual function}

No significant changes in the near visual acuity or near horizontal heterophoria measures were found, whereas reading from the Vuzix NED and the Zeiss NED significantly changed the near point of accommodation values (Table 5 and Fig. 4). A pairwise comparison showed that the Vuzix NED increased both the left (mean $1.65 \mathrm{~cm}$ ) and the right eye (mean $1.55 \mathrm{~cm}$ ) near points of accommodation after 40 min, whereas reading from the Zeiss NED increased the near point of accommodation values of both eyes after 20 min (mean $1.38 \mathrm{~cm}$ ) and $40 \mathrm{~min}$ (mean $2.62 \mathrm{~cm}$ ) and between 20 and $40 \mathrm{~min}(1.24 \mathrm{~cm})$. The changes in the AC values varied among participants, and new clear trends between measurement times were found (Fig. 4).

Table 5. Overall comparison of accommodation values using Kendall's W and Friedman test procedures for several related samples (left) and pairwise comparisons of different reading durations using Wilcoxon's signed ranked test for repeated measurements (right; Holm-Bonferroni correction). Note, $\mathrm{R}=$ right; $\mathrm{L}=$ left; $\mathrm{B}=$ both; 12 = 0-20 min; 23 = 20-40 min; 13 = 0-40 min; and $\mathrm{AC}=$ accommodation.

\begin{tabular}{|c|c|c|c|c|c|c|c|c|}
\hline $\begin{array}{l}\text { Display } \\
\text { Vuzix }\end{array}$ & $\begin{array}{c}\text { Test statistics } \\
\mathrm{N}\end{array}$ & $\begin{array}{c}\text { ACR } \\
20\end{array}$ & $\frac{\mathrm{ACL}}{20}$ & $\mathrm{ACB}$ & Display & Pair & Z & $\begin{array}{l}\text { Asymp. Sig. } \\
\text { (2-tailed) }\end{array}$ \\
\hline \multirow{3}{*}{ Vuzix } & Kendall's W & .270 & .334 & & Vuzix & $\begin{array}{l}\text { ACL13 } \\
\text { ACR13 }\end{array}$ & $\begin{array}{l}-2.653 \\
-2.990\end{array}$ & $\begin{array}{l}0.024 \\
0.009\end{array}$ \\
\hline & $\begin{array}{c}\text { Chi-Square } \\
\text { df }\end{array}$ & $\begin{array}{c}10.800 \\
2\end{array}$ & $\begin{array}{c}13.368 \\
2\end{array}$ & & \multirow{3}{*}{ Zeiss } & ACB13 & -3.418 & 0.003 \\
\hline & Asvmp $\mathrm{Sig}$ & 005 & 001 & & & $\mathrm{ACB} 12$ & -2.951 & 0.006 \\
\hline \multirow[t]{5}{*}{ Zeiss } & $\mathrm{N}$ & & & 21 & & ACB23 & -2.595 & 0.009 \\
\hline & Kendall's W & & & .595 & & & & \\
\hline & Chi-Square & & & 24.986 & & & & \\
\hline & $\mathrm{df}$ & & & 2 & & & & \\
\hline & Asymp. Sig. & & & .000 & & & & \\
\hline
\end{tabular}



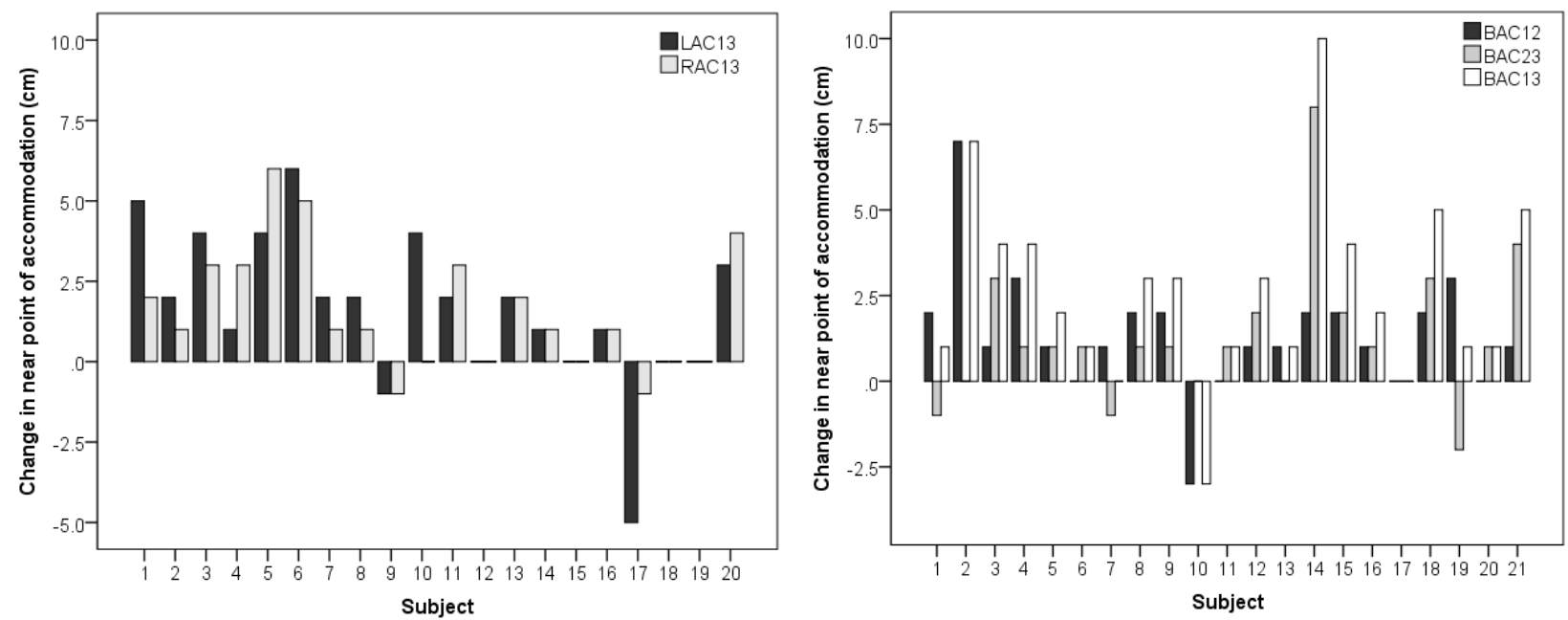

Fig. 4. The changes in the near point of accommodation values by subject (left $=$ Vuzix and right $=$ Zeiss). Note, $L=$ left; $R$ $=$ right B = both; $12=0-20 \mathrm{~min} ; 23=20-40 \mathrm{~min}$; and 13 = 0-40 min. Negative values refer to decreases, and positive values indicate increases in the near point of accommodation values.

Researchers have suggested that vergence and accommodation are linked and that, when one of them changes, the position of the other will also change. However, problems may occur when the vergence must be changed to view the display independently of the optical distance, as with NEDs [41]. As a result, noncongruent accommodation and vergence cues may cause feelings of disorientation and eyestrain [69,40]. Changes in the near point of accommodation of the left and right eyes with the Vuzix NED could have been partially caused by optical differences in the focal and convergence distances, while changes with the Zeiss NED were more likely related to the stimuli layout: the Zeiss NED letter contours had a lower contrast and image sharpness than the Vuzix NED (Figs. 1 and 5, Table 1 and section 3.1.1).
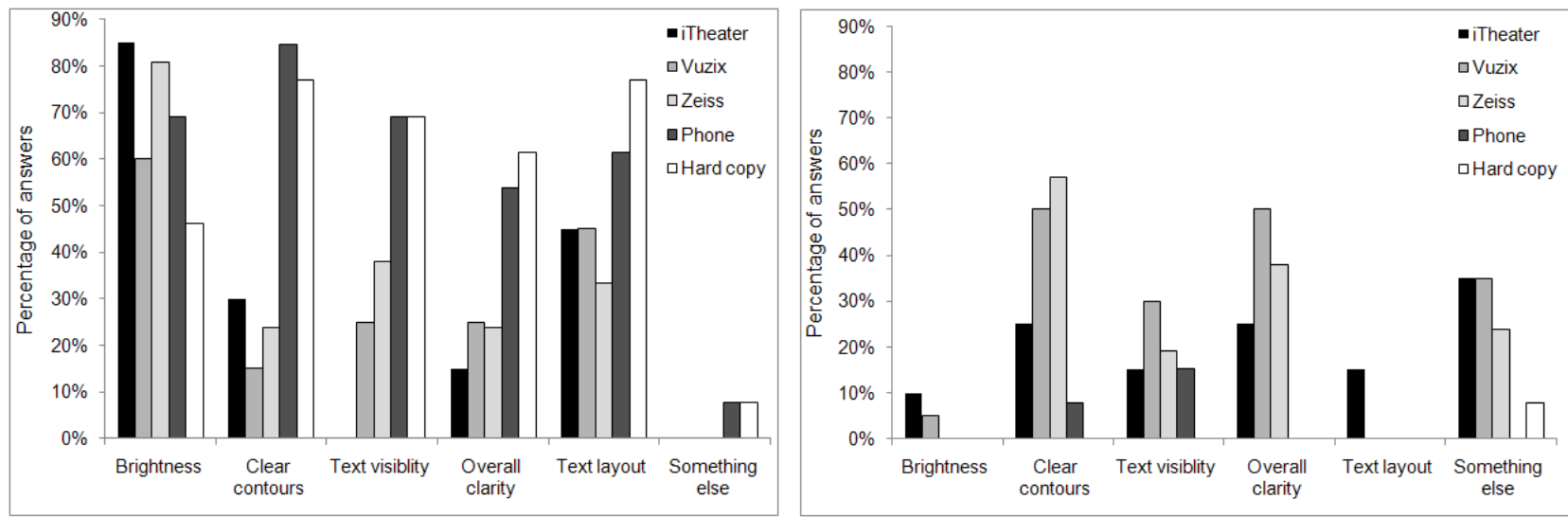

Fig. 5. Good and poor image quality-related features.

\subsubsection{Other subjective opinions and relationships between parameters}

The participants also answered several questions regarding the image quality and reading experience. In one question, subjects were asked to choose several image quality-related features from a list of alternatives. As shown in Fig. 5, readers praised the NED's brightness levels and text layouts, but they thought that the symbol contours and overall clarity were not good enough. 
As expected, the overall image quality of the hard copy was significantly better than the other formats (Table 6 and Fig. 6) [70]. Moreover, the phone's image quality was scored higher than the NEDs' image quality, but no significant differences among the NEDs' image qualities were found. Reading from the hard copy was more enjoyable compared to the electronic screens.

The participants were also asked to approximate suitable reading times for each format. On average, the appropriate reading durations for the phone, the Vuzix NED, the Zeiss NED and the hard copy were $42 \mathrm{~min}$, $28.9 \mathrm{~min}, 35 \mathrm{~min}$ and $71 \mathrm{~min}$, respectively. As expected, the estimated reading duration was positively correlated to the overall image quality $(r=0.407, p<0.01)$ and task enjoyment $(r=0.376, p<0.01)$, whereas an increase in the symptom levels decreased the reading time $(\mathrm{O} 13 \mathrm{r}=-0.298, \mathrm{p}<0.01 ; \mathrm{D} 13 \mathrm{r}=-0.258, \mathrm{p}<0.05$; $\mathrm{T} 13 \mathrm{r}=-0.301, \mathrm{p}<0.01$, VSQ13 $\mathrm{r}=-0.2, \mathrm{p}<0.05)$ and task enjoyment $(\mathrm{N} 13 \mathrm{r}=0.357, \mathrm{p}<0.01 ; \mathrm{O} 13 \mathrm{r}=-0.352$, $\mathrm{p}<0.01 ; \mathrm{D} 13 \mathrm{r}=-0.358, \mathrm{p}<0.01 ; \mathrm{T} 13 \mathrm{r}=-0.389, \mathrm{p}<0.01$, VSQ13 $\mathrm{r}=-0.273, \mathrm{p}<0.01)$ and negatively influenced the overall image quality $(\mathrm{N} 13 \mathrm{r}=-0.233, \mathrm{p}<0.05 ; \mathrm{O} 13 \mathrm{r}=-0.261, \mathrm{p}<0.01 ; \mathrm{T} 13 \mathrm{r}=-0.262, \mathrm{p}<0.01)$ $[19,36,3,2,8]$. No significant differences in the headset fit or the opinion change scores were observed, although a positive relationship between the opinion change and task enjoyment was observed $(r=0.192, p<0.05)$; the Zeiss NED could be used without personal glasses, but, in this study, this was not an option. Task enjoyment was also positively correlated with the overall image quality $(r=0.526, p<0.01)[36,53]$.

Participants with previous NED experience were more critical of the image quality of the text on the NED displays $(r=-0.343, p<0.01)$ [19], whereas participants who were more susceptible to motion sickness in daily life reported higher eyestrain $(r=0.271, \mathrm{p}<0.01)$, disorientation $(r=0.305, \mathrm{p}<0.01)$, oculomotor symptoms $(\mathrm{r}=$ $0.274, p<0.01)$, and total symptom severity levels $(r=0.272, p<0.01)$ when the text was read from an electronic screen $[50,42]$.

In addition to other opinions and comments, participants thought the NED-related distortions on different parts of the screen (uneven contrast and curvature changes on the screen) and problems with text visibility clearly influenced viewing comfort and task enjoyment [2,3,57]. Several participants also reported symptoms of pattern glare, which were previously connected to headaches and migraines (cf., [71,72]).

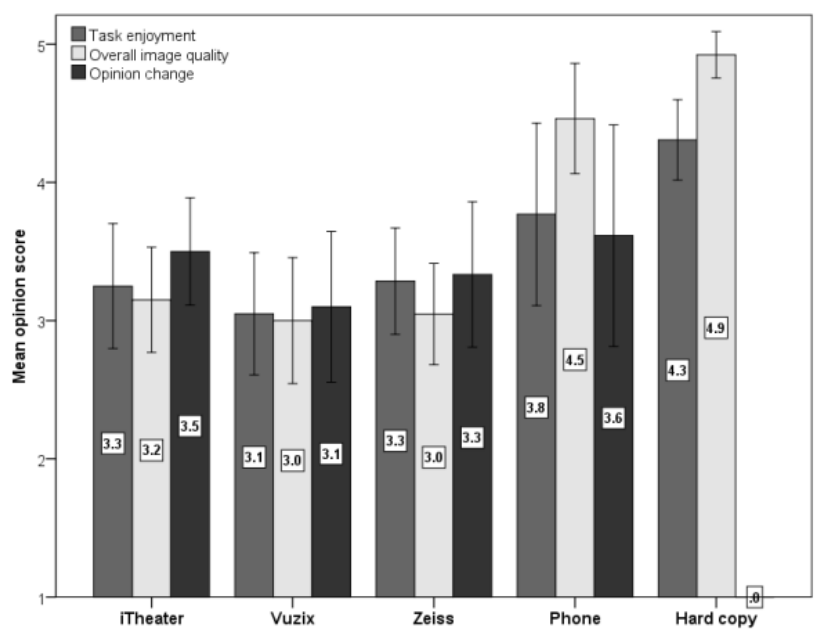

Fig. 6. The mean opinion scores for task enjoyment, overall image quality and opinion change. A value of 1 indicates not enjoyable/very poor/clearly in the negative direction; 3 indicates moderate; and 5 indicates very enjoyable/very good/clearly in the positive direction. Vertical lines represent standard errors. 
Table 6. The significant differences in task enjoyment, image quality and reading duration for pairs of media formats (nonparametric tests for 2 independent samples SPSS).

\begin{tabular}{|c|c|c|c|c|}
\hline Media & Statistics & $\begin{array}{c}\text { Task } \\
\text { enjoyment }\end{array}$ & $\begin{array}{l}\text { Overall image } \\
\text { quality }\end{array}$ & $\begin{array}{l}\text { Reading } \\
\text { duration }\end{array}$ \\
\hline $\begin{array}{c}\text { Hard copy } \\
\text { iTheater }\end{array}$ & \begin{tabular}{|} 
Mann-Whitney U \\
Wilcoxon W \\
Z \\
Asymp. Sig. (2-tailed)
\end{tabular} & $\begin{array}{c}49.000 \\
259.000 \\
-3.167 \\
.002\end{array}$ & $\begin{array}{c}9.500 \\
219.500 \\
-4.669 \\
.000\end{array}$ & \\
\hline $\begin{array}{c}\text { Hard copy } \\
\text { Vuzix }\end{array}$ & \begin{tabular}{|} 
Mann-Whitney U \\
Wilcoxon W \\
Z \\
Asymp. Sig. (2-tailed)
\end{tabular} & $\begin{array}{c}33.500 \\
243.500 \\
-3.750 \\
.000\end{array}$ & $\begin{array}{c}10.000 \\
220.000 \\
-4.629 \\
.000\end{array}$ & $\begin{array}{c}39.500 \\
249.500 \\
-3.158 \\
.002\end{array}$ \\
\hline $\begin{array}{c}\text { Hard copy } \\
\text { Zeiss }\end{array}$ & \begin{tabular}{|} 
Mann-Whitney U \\
Wilcoxon W \\
Z \\
Asymp. Sig. (2-tailed)
\end{tabular} & $\begin{array}{c}47.000 \\
278.000 \\
-3.424 \\
.001\end{array}$ & $\begin{array}{c}3.500 \\
234.500 \\
-4.900 \\
.000\end{array}$ & $\begin{array}{c}48.000 \\
238.000 \\
-2.698 \\
.007\end{array}$ \\
\hline $\begin{array}{c}\text { Hard copy } \\
\text { Phone }\end{array}$ & \begin{tabular}{|} 
Mann-Whitney U \\
Wilcoxon W \\
Z \\
Asymp. Sig. (2-tailed)
\end{tabular} & & $\begin{array}{c}51.500 \\
142.500 \\
-2.188 \\
.029\end{array}$ & \\
\hline $\begin{array}{l}\text { iTheater } \\
\text { Phone }\end{array}$ & \begin{tabular}{|} 
Mann-Whitney U \\
Wilcoxon W \\
Z \\
Asymp. Sig. (2-tailed)
\end{tabular} & & $\begin{array}{c}32.000 \\
242.000 \\
-3.765 \\
.000\end{array}$ & \\
\hline $\begin{array}{l}\text { Vuzix } \\
\text { Phone }\end{array}$ & \begin{tabular}{|} 
Mann-Whitney U \\
Wilcoxon W \\
Z \\
Asymp. Sig. (2-tailed)
\end{tabular} & & $\begin{array}{c}33.000 \\
243.000 \\
-3.707 \\
.000\end{array}$ & \\
\hline $\begin{array}{l}\text { Zeiss } \\
\text { Phone }\end{array}$ & \begin{tabular}{|} 
Mann-Whitney U \\
Wilcoxon W \\
Z \\
Asymp. Sig. (2-tailed)
\end{tabular} & & $\begin{array}{c}28.500 \\
259.500 \\
-3.982 \\
.000\end{array}$ & \\
\hline
\end{tabular}

\section{CONCLUSION}

Comparing the reading experiences with three different NEDs, a small-size display, and a hard copy showed clear differences among the reading devices. As expected, long-term reading with a hard copy was the most comfortable experience, although even it caused mild eyestrain. Reading an e-book from a small-sized display was a relatively comfortable experience, but, similar to previous results, it caused eyestrain, especially when the reading session lasted more than $20 \mathrm{~min}$. On the basis of subjective opinions, the limitations in the text layout, especially when a small type size was used, were the most critical characteristics for viewing discomfort with a small-sized display. Even though reading from a small sized display induced more symptoms during the second half of the reading session, the overall symptom levels were lower or comparable with NEDs, and the appropriate reading duration for the phone was thought to be as long as $42 \mathrm{~min}$.

Reading experiences with NEDs are variable and depend on the device. NEDs may show problems with optics and headset fit, and the observable display resolution is relatively low compared to other electronic screens of similar image size on the market. Furthermore, content optimization to ensure the best possible image quality is difficult and is occasionally impossible. Additionally, other NED-related features, such as the 
unnatural gaze angle, headset movement relative to the head, use context, nature of the task, individual differences and viewing duration, can interact and induce symptoms related to visually induced motion sickness and eyestrain and can cause some changes in visual function. Even though participants thought that the distortions on different parts of the screen and problems with text visibility clearly influenced the viewing comfort and task enjoyment, the appropriate session duration of NEDs with reading tasks was estimated to be approximately half an hour. Generalizing these results should be performed with caution because our findings are device-dependent despite the representativeness of the tested NEDs. For example, one could argue that if the NED resolution exceeded that of the human visual system (similar to paper), it could improve the viewing comfort. This proposition sounds reasonable, but the optical quality (e.g., aberrations, tolerances), binocular differences (e.g., focus distance vs. convergence, luminance asymmetry, vertical misalignment), and mechanical quality of the display adjustments (e.g., nose bridge, interpupillary distance setting) may be equally important. Achieving a higher resolution on a NED without sacrificing the other parameters is nonetheless a good goal.

Viewing content with fewer details or watching motion scenes for shorter periods of time on NEDs is not likely to cause symptom levels similar to our findings. Thus, using NEDs could be a comfortable experience in these applications. However, several improvements in the optics and headset should be implemented before NEDs can be considered to be competitive with other reading displays in the market. Reading an e-book should be enjoyable, engaging, and fun and should not cause nausea or other symptoms of visually induced motion sickness.

\section{ACKNOWLEDGMENT}

The authors would like to express their appreciation to Dr. B. Bilcu from the Tampere University of Technology for her advice and comments on the manuscript.

\section{REFERENCES}

1. K. Rayner, I. Pollatsek, The psychology of reading. Lawrence Erlbaum Associates, Inc., Publishers, New Jersey (1989).

2. B. Hill, The Magic of Reading, http://www.poynterextra.org/msfonts/osprey.doc (retrieved on 1.01.11, Version 1.0 04/27/99).

3. V. Nell, The psychology of reading for pleasure: needs and gratifications, Reading Reseach Quarterly 23 (1988) 6-50.

4. A. Dillon, Reading from paper versus screens: a critical review of the empirical literature, Ergonomics 35 (1992) $1297-1326$.

5. M.C. Dyson, How physical text layout affects reading from screen, Behaviour \& Information Technology 23 (2004) $377-393$.

6. J.E. Sheedy, The physiology of eyestrain, Journal of Modern Optics, 54 (2007) 1333-1341, DOI:10.1080/09500340600855460.

7. J.E. Sheedy, J. R. Hayes, and J. Engle, Is All Asthenopia the Same?, Optom Vis Sci. 80 (2003) 732-739.

8. M.A. Tinker, (1963). Legibility of print. Ames, IA: Iowa State University Press.

9. J. Sheedy, R. Smith, J. Hayes, Visual effects of the luminance surrounding a computer display, Ergonomics 48 (2005) 11141128 .

10. J.E. Sheedy, M. Subbaram, A. Zimmerman, J.R. Hayes, Text legibility and the letter superiority effect, Human Factors 47 (2006) 797-815.

11. P.A. Kolers, R.L. Duchnicky, D.C. Ferguson, Eye movement measurement of readability of CRT displays, Human Factors 23 (1981) $517-527$.

12. R.L. Duchnicky, P.A. Kolers, Readability of text scrolled on visual display terminals as a function of window size, Human Factors 25 (1983) $683-692$.

13. D. Boyarski, C. Neuwirth, J. Forlizzi, S. Regli, A study of fonts designed for screen display, Proceedings of CHI' 98 (1998) $87-$ 94.

14. M.L. Bernard, B.S. Chaparro, M.M. Mills, C.G. Halcomb, Comparing the effects of text size and format on the readibility of computer-displayed Times New Roman and Arial text, International Journal of Human-Computer Studies 59 (2003) 823-835, DOI: 10.1016/S1071-5819(03)00121-6.

15. I. Darroch, J. Goodman, S. Brewster, P. Gray, The Effect of Age and Font Size on Reading Text on Handheld Computers, INTERACT 20053585 (2005) $253-266$.

16. Z. Liu, D. Stork, Is paperless really more? Rethinking the role of paper in the digital age, Communications of the ACM, 42 (2000) 94-97.

17. Z. Liu, Print vs. electronic resources: A study of user perceptions, preferences, and use, Information Processing and Management, 42 (2006) 583-592. 
18. R.A. Tyrrell, H.W. Leibowitz, The relation of vergence effort to reports of visual fatigue following prolonged near work, Hum Factors 32 (1990) 341-57.

19. M. Pölönen, Thesis: A head-mounted display as a personal viewing device: Dimensions of subjective experiences Helsinki Univerity 2010, ISBN 978-952-10-6386-2.

20. P.A. Howarth, Oculomotor Changes within Virtual Environments, Applied Ergonomics 30 (1999) 59-67.

21. P.A. Howarth, P.J. Costello, The Occurrence of Virtual Simulation Sickness Symptoms when an HMD was used as a Personal Viewing System, Displays 18 (1997) 107-116.

22. P.A. Howarth, The adverse health and safety effects of viewing visual images, Displays 29 (2008) 45-46.

23. L.J. Hettinger, G.E. Riccio, Visually-induced motion sickness in virtual environments, Presence 1(3) (1992) 306-310.

24. R. Patterson, M.D. Winterbottom, B.J. Pierce, Perceptual Issues in the Use of Head-Mounted Visual Displays, Human Factors 48 (2006) 555-573.

25. M. Mon-Williams, A. Plooy, R. Burgess-Limerick, J. Wann, Gaze angle: a possible mechanism of visual stress in virtual reality headsets, Ergonomics 41(1998) 280-285.

26. R. Burgess-Limerick, A. Plooy, D.R. Ankrum, The effect of imposed and self-selected computer monitor height on posture and gaze angle, Clinical Biomechanics 13 (1998) 584-592.

27. R. Burgess-Limerick, M. Mon-Williams, V.L. Coppard, Visual display height. Human Factors 42 (2000) 140-150.

28. J.J. Whitestone, K.M. Robinette, Fitting to maximize performance of HMD systems. In J. Melzer, \& K. Moffitt. (Eds.), Head Mounted Displays, Designing for the User (pp. 175-206). McGraw Hill Publishing, New York (1997).

29. W. Jaschinski, H. Heuer, H. Kylian, Preferred position of visual displays relative to the eyes: A field study of visual strain and individual differences, Ergonomics 41 (1998) 1034-1049.

30. H.C. Self, Critical tolerances alignment and image differences for binocular helmet-mounted displays (Technical Report AAMRL-TR-86-019). Wright-Patterson AFB, OH: Armstrong Aerospace Medical Research Laboratory (1986).

31. M. Pölönen, V. Aaltonen, G. Nyman, J. Häkkinen, Influence of the monocular near-to-eye display position on the visual system during dual-task performance, Journal of the Society for Information Display 16 (2008) 1083-1087.

32. S. Hill, K. Kroemer, Preferred declination of the line of sight, Human Factors 28 (1986) 127-134.

33. O. Merhi, E. Faugloire, M. Flanagan, T.A. Stoffregen, Motion sickness, console video games, and head-mounted displays, Human Factors 49 (2007) 920-934.

34. H.C. Wu, C.L. Lee, C.T. Lin, Ergonomic evaluation of three popular Chinese e-book displays for prolonged reading, International Journal of Industrial Ergonomics 37 (2007) 761-770, DOI: 10.1016/j.ergon.2007.06.003.

35. J. Richardson, A. Dillon, C. McKnight, The effect of window size on reading and manipulating electronic text, Proceedings of the Ergonomics Society's 1989 Annual Conference (1989) 474 - 479.

36. M. Pölönen, J. Häkkinen, Near-to-eye display - an accessory for handheld multimedia devices: subjective studies, Journal of Display Technology 5 (2009) 358- 367.

37. S. Rushton, M. Mon-Williams, J.P. Wann, Binocular vision in a bi-ocular world. New-generation head-mounted displays avoid causing visual deficit, Displays 4 (1994) 255-260.

38. J. Wann, M. Mon-Williams, What does virtual reality need?: human factors issues in the design of three-dimensional computer environments, International Journal of Human-Computer Studies 44 (1996) 829-847.

39. K. Ukai, P.A. Howarth, Visual fatigue caused by viewing stereoscopic motion images: Background, theories, and observations, Displays 29 (2008) 106-116.

40. M. Mon-Williams, J. Wann, S. Rushton, Binocular vision in a virtual world: Visual deficits following the wearing of a headmounted display, Opthalmic and Physiological Optics 13 (1993) 387-39.

41. G.K. Edgar, Accommodation, cognition, and virtual image displays: A review of the literature, Displays 28 (2007) 45-59.

42. R. Kennedy, N. Lane, K. Berbaum, M. Lilienthal, Simulator Sickness Questionnaire: An Enhanced Method for Quantifying Simulator Sickness, International Journal of Aviation Psychology 3(3) (1993) 203-220.

43. S. Cobb, S. Nichols, A. Ramsey, J. Wilson, Virtual Reality-Induced Symptoms and Effects (VRISE), Presence: Teleoperators \& Virtual Environments 8 (1999) 169-186.

44. R. Kennedy, K. Stanney, W. Dunlap, Duration and Exposure to Virtual Environments: Sickness Curves During and Across Sessions, Presence: Teleoperators \& Virtual Environments 9 (2000) 463-472.

45. V. Aaltonen, M. Pölönen, The Effect of Viewing Duration on Visual Comfort with Near-to-Eye Displays, in SID 2009, DIGEST, 812-814.

46. D.R. Lampton, E.M. Kolasinski, B.W. Knerr, J.P. Bliss, J.H. Bailey, B.G. Witmer, Side effects and aftereffects of immersion in virtual environments, in Proceedings of the Human Factors Society 38th Annual Meeting (1994) 1154-1157.

47. C. Regan, An investigation into nausea and other side-effects of head-coupled immersive virtual reality, Virtual Reality 1 (1995) 17-32.

48. R.S. Kennedy, J.E. Fowlkes, Simulator sickness is polygenic and polysymptomatic: Implications for research, International Journal of Aviation Psychology 2(1) (1992) 23-38.

49. P. DiZio, J.R. Lackner, Influence of gravitoinertial force level on vestibular and visual velocity storage in yaw and pitch, Vision Research 32 (1992) 111-120.

50. L.J. Hettinger, G.E. Riccio, Visually-induced motion sickness in virtual environments, Presence 1(3) (1992) 306-310.

51. T.A. Stoffregen, E. Faugloire, K. Yoshida, M.B. Flanagan, O. Merhi, Motion sickness and postural sway in console video games, Human Factors 50 (2008) 322-331.

52. W.T. Lo, R.H.Y. So, Cybersickness in the presence of scene rotational movements along different axes, Applied Ergonomics 32 (2001) 1-14.

53. M. Pölönen, T. Järvenpää, J. Häkkinen, Comparison of Near-to-Eye Displays: Subjective Experience and Comfort, Journal of Display Technology 6 (2010) 27-35.

54. T. Järvenpää, M. Pölönen, Advances in Near-to-Eye Display Optical Characterization, Optical characterization and ergonomical factors of near-to-eye displays, Journal of the Society for Information Display 18 (2010) 285-292.

55. J. Sheedy, N. Bergström, Performance and comfort on near-eye computer displays, Optometry and Vision Science 79 (2002) 306-312

56. E. Peli, The visual effects of head-mounted display (HMD) are not distinguishable from those of desk-top computer display, Vision Research 38 (1998) 2053-2066. 
57. H. Knoche, J. McCarthy, Mobile users' needs and expectations of future multimedia services, in Proc. WWRF12, 2004.

58. H. Knoche, M. Sasse, The sweet spot: How people trade off size and definition on mobile devices, in Proc. 16th ACM Int. Conf. on Multimedia (2008) 21-30.

59. Dillon, J. Richardson and C. McKnight, The effect of display size and text splitting on reading lengthy text from the screen, Behaviour and Information Technology 9 (1990) 215-227.

60. H. Knoche, J. McCarthy, M.A. Sasse, Reading the Fine Print: The Effect of Text Legibility on Perceived Video Quality in Mobile TV, Proceedings of the 14th annual ACM international conference on Multimedia (2006) 727-730.

61. J. Laarni, I. Kojo, L.Kärkkäinen, Reading and searching information on small display screens. In D. de Waard, K. Brookhuis, J. Moraal, \& A. Toffetti (Eds.), Human Factors in Transportation, Communication, Health, and the Workplace (2002) $505-516$.

62. J. Wolffsohn, A review of current knowledge on Electronic Vision Enhancement Systems for the visually impaired, Ophthalmic \& physiological optics 23 (2003) 35-42.

63. R.C. Peterson, J.S. Wolffsohn, M.Rubinstein, J. Lowe, Benefits of electronic vision enhancement systems (EVES) for the visually impaired, American Journal of Ophthalmology 136 (2003) 1129-1135, ISSN 0002-9394, DOI: 10.1016/S00029394(03)00567-1.

64. P.A. Howarth, H.O. Istance, The association between visual discomfort and the use of visual display units, Behaviour and Information Technology 4 (1985) 135-149.

65. G.B. Mills, L.J. Weldon, Reading text from computer screens, ACM Computing Surveys 19 (1987) 329-358.

66. P. Muter, Interface design and optimization of reading of continuous text, in H. van Oostendorp and S. de Mul (Eds) Cognitive Aspects of Electronic Text Processing, Norwood, New Jersey: Ablex, 1996, pp. $161-180$.

67. K.M.Stanney, R.R. Mourant, R.S. Kennedy, Human factors issues in virtual environments: a review of the literature, Presence: Teleoperators and Virtual Environments 7 (1998) 327-351.

68. S. Sharples, S. Cobb, A. Moody, J.R. Wilson, Virtual reality induced symptoms and effects (VRISE): Comparison of head mounted display (HMD), desktop and projection display systems, Displays 29 (2008) 58-69.

69. J.H. Iavecchia, H. Iavecchia, S.R. Roscoe, Eye accommodation to head-up virtual images, Hum. Factors 30 (1988) 698-702.

70. Chu, M. Rosenfield, J.K. Portello, J.A. Benzoni, J.D. Collier, A comparison of symptoms after viewing text on a computer screen and hardcopy, Ophthalmic Physiol Opt 31 (2011) 29-32. doi: 10.1111/j.1475-1313.2010.00802.x

71. D.A. Marcus, M.J. Soso, Migraine and striped-induced visual discomfort, Arch Neurol 46 (1989) 1129-32.

72. A.J. Wilkins, R. Patel, P. Adjamian B.J.W. Evans, Tinted spectacles and visually sensitive migraine, Cephalalgia 22 (2002) 711-719.

73. T.J. Slattery, K. Rayner, The influence of text legibility on eye movements during reading, Applied Cognitive Psychology 24 (2010) 1129-1148.

74. T. Mustonen, M. Olkkonen, J. Häkkinen, Examining mobile phone text legibility while walking, Proceedings of the ACM Conference on Human Factors in Computing Systems (2004) 1243 -1246.

75. J. Häkkinen, M.Pölönen, M.Salmimaa, J. Hautanen, Reading experience with curved hand-held displays, Journal of the Society for Information Display 16 (2008) 1099-1103.

76. J. Häkkinen, J. Takatalo, M. Pölönen, G. Nyman, Simulator sickness in virtual display gaming: A comparison of stereoscopic and non-stereoscopic situations, Proceedings of the 8th conference on Human-computer interaction with mobile devices and services MobileHCI '06, ACM International Conference Proceeding Series; 159 (2006) 227-229.

77. J. Häkkinen, T.Vuori, M. Puhakka, Simulator sickness and postural sway after HMD use, Proceedings of the IEEE International Conference on Systems, Man and Cybernetics (2002) 147-152.

78. M.F. Deering, The Limits of Human Vision, http://www.swift.ac.uk/about/files/vision.pdf

79. W.S. Geisler, Physical limits of acuity and hyperacuity, J. Opt. Soc. Am. 1(7) (1984) 775-782. 